\title{
The COVID Warriors: The Psychological Experiences of Nurses Worked in COVID 19 Care Areas in Tertiary Care Hospital: A Qualitative Study
}

Rebecca Herald $^{1}$, Srinithya Raghavan ${ }^{2}$, J. Subbulakshmi ${ }^{3}$, Kamlesh Chandelia ${ }^{4}$, Deepika Khakha ${ }^{5 *}$, D K Sharma ${ }^{6}$

${ }_{1,2,3}$ Nursing In Service Educator, Main Hospital, AIIMS, New Delhi.

${ }^{4}$ Chief Nursing Officer, AIIMS, New Delhi.

$5^{*}$ Assistant Professor, College of Nursing, AIIMS, New Delhi.

${ }^{6}$ Medical Superintendent, AIIMS, New Delhi.

Article Details
Article Type: Research Article
Received date: $25^{\text {th }}$ March, 2021
Accepted date: $25^{\text {th }}$ April, 2021
Published date: $18^{\text {th }}$ May, 2021
"Corresponding Author: Deepika Khakha, Assistant Professor, College of Nursing, AIIMS, New Delhi. E-mail: dckhakha@,
gmail.com
Citation: Herald, R., Raghavan, S., J. Subbulakshmi, Chandelia, K., Khakha, D., Sharma, D.K. (2021). The COVID Warriors:
The Psychological Experiences of Nurses Worked in COVID 19 Care Areas in Tertiary Care Hospital: A Qualitative Study. $J$
Comp Nurs Res Care 6(1):173. doi: https://doi.org/10.33790/jcnrc1100173.
Copyright: $\odot 2021$, This is an open-access article distributed under the terms of the Creative Commons Attribution License
4.0, which permits unrestricted use, distribution, and reproduction in any medium, provided the original author and source are
credited.

\section{Introduction}

Coronavirus represents a major group of viruses mostly affecting human beings through zoonotic diseases. Widely believed to have originated in the Hubei province in China in November 2019, COVID-19, the infectious disease caused by severe acute respiratory syndrome coronavirus 2 (SARS-CoV-2), is spreading fast across the world and was declared a pandemic by WHO on March 11, 2020, [1]. The recent outbreak of COVID-19 in several countries is similar to the previous outbreaks of SARS and the Middle East respiratory syndrome (MERS) that emerged in 2003 and 2012 in China and Saudi Arabia, respectively. SARS is caused by SARS-CoV, where as SARS-CoV-2 causes COVID-19. SARS-CoV-2 is more transmissible than SARS-CoV. The two possible reasons could be (i) the viral load (quantity of virus) tends to be relatively higher in COVID-19positive patients, especially in the nose and throat immediately after they develop symptoms, and (ii) the binding affinity of SARS-CoV-2 to host cell receptors is high [2].

The first SARS-CoV-2 positive case in India was reported in the state of Kerala on January 30th, 2020. Subsequently, the number of cases drastically rose.

Studies have shown that during sudden natural disasters and infectious diseases, nurses will sacrifice their own needs to actively participate in the anti-epidemic work and make selfless contributions out of moral and professional responsibility [3].

At the same time, nurses would be in a state of physical and mental stress and feel isolated and helpless in the face of health threats and pressure from the high-intensity work caused by such public health emergencies [4]. There are many studies on various aspects of COVID 19, and few on psychological aspects of nurses working in COVID areas.

Hence this study aims to explore the in-depth subjective experiences of nurses working in COVID areas.

\section{The objective of the study}

It is to explore and understand the psychological experiences that they have experienced while giving care to the COVID 19 patients.

\section{Methodology}

Study Design: It is a Phenomenological method to qualitatively study the psychological experiences of nurses who had worked and been working in COVID care areas of All India Institute of Medical Sciences.
Population: Nurses working in clinical areas of COVID 19 wards.

Sample: Clinical nurses working in Jai Prakash Narayan Apex Trauma Centre, Emergency wards dedicated for COVID 19 patients were taken as study participants. Convenient sampling was used with the inclusion criteria of nurses who worked in COVID areas and willing to participate in the study. A total of fifteen nurses were interviewed till the data saturation.

Settings: COVID 19 areas, All India Institute of Medical Sciences. Tools

A demographic profile pro forma and Interview with a list of questions were used as tools. The questions were formed after a thorough literature review and finalized by experts. And the following questions were asked to the participants.

1. What was your reaction/response when you were posted in the COVID area?

2. What was your idea about the pandemic and COVID 19 ?

3. What were the stressors you experienced?

4. What was your family's response towards your posting in the COVID area?

5. What was your experience with COVID patients? ( Physical \& Psychological)

6. What was your experience with Personal Protective Equipment?

7. What concerned you most about your family?

8. What was your experience with colleagues and what advice/ suggestions would you like to give to your colleagues who would be posted in COVID areas?

9. How do you feel after having worked in the COVID area? ( Psychologically \& Physically)

10. What were your coping strategies?

Demographic profile: Included Age, Gender, Educational Qualification, Length Of the Clinical Experience of the Sample.

\section{Data collection}

Interviews were taken from 15.09.20 to 28.09.20. The participants were interviewed in their convenient times in a separate room. Interviews were conducted with face-to-face interactions. The purpose and importance of the study were explained to the participants. After 
initial rapport building with the study participants. Researchers conducted the face-to-face interview. It took $20-30$ minutes for each interview. Clarification, restating and active listening was used to collect the information. And the responses of the participants were recorded using a mobile recorder.

\section{Data Analysis}

The recordings were written down carefully on the same day by the researchers. The researchers transformed the recordings into verbatim, and finally into meaningful statements and then into themes to draw out inferences to analyze qualitative data. Member check was done after the analysis.

\section{Ethical permission}

Permission from Institute Ethical Committee was obtained before starting the study. All participants were provided an information sheet and written consents were obtained from them.

\section{Review of Literature}

The nurses caring for COVID-19 patients felt extreme physical fatigue and discomfort caused by the outbreak, intense work, large number of patients, and lack of protective materials, which was consistent with the studies on the outbreak of MERS-CoV [5] and Ebola [5]. The physical exhaustion, psychological helplessness, health threat, lack of knowledge, and interpersonal unfamiliarity under the threat of epidemic disease led to a large number of negative emotions such as fear, anxiety, and helplessness [6]. Many studies have shown that epidemic outbreaks can cause psychological trauma for caregivers [7]. It is known that coping style, cognitive evaluation, and social support are all mediators of stress. Studies have shown that psychological adaptation and social support play an intermediary role in psychological rehabilitation under outbreak stress [8]. Pressure of the epidemic may prompt nurses to use their medical and psychological knowledge to actively or passively make psychological adjustments. It has been demonstrated that all coping measures under the epidemic disaster can alleviate stress and promote mental health [9]. Generally nurses can adjust their cognitive rationality to adapt to the epidemic, which may also be related to health care professionals' rich medical knowledge and more rational and positive attitude [10].

\section{Results}

Demographic Data:

\begin{tabular}{|c|c|c|}
\hline S no & Demographic profile & Percentage n (\%) \\
\hline 1. & Age & 20 to 30 years \\
\hline 2. & Sex & $\begin{array}{l}\text { Female : } 66.6 \% \\
\text { Male : } 33 \%:\end{array}$ \\
\hline 3. & Marital Status & $\begin{array}{l}\text { Married : } 46.6 \% \\
\text { Unmarried : } 53.3 \%\end{array}$ \\
\hline 4. & Qualification & $\begin{array}{l}\text { Diploma in Nursing : } 13 \% \\
\text { B.Sc in Nursing: } 73.3 \% \text { : } \\
\text { M.Sc in Nursing: } 13 \% \text { : }\end{array}$ \\
\hline 5. & $\begin{array}{l}\text { Total Experience in } \\
\text { Nursing }\end{array}$ & $\begin{array}{l}\text { 02-05 Years: } 60 \% \text { : } \\
\text { 06-10Years: } 13 \% \text { : }\end{array}$ \\
\hline 6. & $\begin{array}{l}\text { Experience in All } \\
\text { India Institute of } \\
\text { Medical Sciences. }\end{array}$ & $\begin{array}{l}\text { 02-05 Years: } 66.6 \% \text { : } \\
\text { 06-10 Years: } 20 \% \text { : } \\
\text { 11-20 Years: } 13 \% \text { : }\end{array}$ \\
\hline 7. & Comorbidities & $\begin{array}{l}\text { Yes: } 6.6 \% \\
\text { No: } 93.3 \%\end{array}$ \\
\hline 8. & $\begin{array}{l}\text { Any Psychiatric } \\
\text { illness }\end{array}$ & Nil \\
\hline 9. & Experience in COVID & $\begin{array}{l}\text { Less than } 15 \text { days: } 6.6 \% \\
01 \text { Month to } 02 \text { Months: } 20 \% \\
\text { More than } 02 \text { Months: } 73.3 \% \text { : }\end{array}$ \\
\hline
\end{tabular}

\section{Study Findings:}

Theme 1: Knowledge:

\section{Knowledge about COVID 19}

Most of the nurses knew about the disease and how it became a pandemic, that it had originated in Wuhan, China and later had caused havoc in Italy. All of them had attended training on donning and doffing, respiratory and mask etiquettes, and standard precautions, so the concept of PPE and Biomedical waste was clear in their minds. Most of them knew that it was an airborne disease and is very infectious. All of them reported their knowledge of hand hygiene and social distancing.

\section{Theme 2: Experience in COVID area/PPE}

\section{Experience with PPE}

The majority of the nurses reported there was a sufficient quantity of PPE available and there was no shortage, however, it was also reported by most of them that at different times the different quality of PPE was provided out of which some was so substandard that it tore off easily and caused more physical discomfort.

"Had to doff early because PPE had torn off", slippery shoe covers, bulky PPE, "fogging", Many of them reported decreased vision and hearing which made nursing care difficult to render.

"Difficult IV Cannulation", Difficult to identify infusion', "asked colleagues to identify infusions because of fogging' "Increased risk of self pricking due to fogging", "difficulty in following instructions due to decreased hearing",

Physical discomforts like increased perspiration, nausea, vomiting, breathlessness, suffocation, gastritis, distended bladder, urticaria, nose pain and ulcers, ear pain, weight loss, and chest discomfort

"Increased risk of fall due to slippery shoe covers", "felt dehydrated due to increased sweating", "post duty tiredness due to bulky PPE", "I lost weight", "I had gastritis". 
Nurses expressed that they had fear of fall/slip as the goggles were foggy and the shoe covers were slippery and many of them reported that they had to abstain from drinking water, taking food to avoid emptying bladder and bowels while PPE.

Overall the experience of wearing PPE was distressing as reported by one participant "wearing PPE was hell".

\section{Experience with colleagues}

All of the participants expressed that their colleagues were cooperative, supportive, helpful, and collaborative. Participants had the chance to work with nurses from other centers also. The experience reported by the participants was

"good" "helpful" "cooperative" 'were willing to exchange assignments" "friendly"

\section{Suggestions to colleagues:}

All the participants emphasized the importance of complete donning with a checklist and doffing in utmost care. The participants also stressed the importance to have adequate knowledge and skill about COVID 19 and PPE. They also suggested proper diet, hydration, and adequate sleep and rest.

The participants encouraged other nurses to work in the COVID pandemic as it would be a new and great learning experience. The following were expressed by them. "golden opportunity" "be careful with doffing" "don't remove PPE
in-between" "best time in Nursing"

\section{Theme 3: Physical and psychological Stressors:}

\section{Physical Stress}

Most of the nurses have had health problems like nausea, vomiting, and aspiration, dehydration, indigestion, gastritis, syncope attacks, etc. These complaints were related to PPE and odd duty hours.

"Suffocating", "Fainting", "nauseated", "I Vomited and aspirated", "Excessive Sweating", "I licked my sweat to moisten my lips".

Loss of weight was reported by the nurses, barring a few exceptions who reported weight gain.

\section{Fear and Anxiety}

Most of our nurses expressed that they had fear and were anxious initially when they heard about their posting in COVID care areas. They exhibited their fear, Shock anger, and anxiety as expressed by their opinions.

"Scared", "I was shocked", "I was angry", "Why only me", "Not informed before", "Panic"

A minor number of nurses expressed pride, curiosity, and excitement on hearing about their postings.

"I was so proud", "I was excited", "So curious",

Still, a few volunteered themselves to be posted in COVID care areas.

\section{Mental Stress: (Burden)}

Nursing COVID 19 patients particularly geriatric and pediatric group was tough and mentally fatiguing, as they had to be given individual attention.

"I had to have a baby in my arm", "I had to assist them to the toilet", Helplessness and anger were exhibited by some nurses when they saw young patients were dying within hours of admission due to the quick progression of the disease. Discouragement and demotivation plagued some of the nurses that despite doing their maximum, patients could not survive. Nurses also expressed ethical frustration when they were unable to discharge more professional duties due to their perceived shortage of nursing staff.

"I felt Helpless", "We felt that we are giving false assurance to the patient", "Body packing of young patients was very traumatic", "Pathetic".

\section{Family Response to posting in COVID area}

A wide spectrum of responses was reported by the family members varying from shock, fear, anxiety, worry, panic, stress, crying, disappointment, supportive, happy, encouraging, proud, to no response at all. Few nurses did not inform their families about their posting.

"Mother started crying", "Husband was not willing but In-laws were encouraging", "Parents were Happy, I was a Hero in my home town. My Video was telecast in the town", "my sister was very supportive and counseled me", "my mother was already working in COVID hospital so my posting was not an issue".

\section{Concerns about Family}

Most of the nurses were concerned about family members getting infected through them. Others who were staying away from their families did not want the family members to be anxious and stressed about their COVID care duty, so did not share information regarding their posting with their family.

Some nurses were confident and stayed with their families taking isolation precautions, while others who stayed alone in Delhi were anxiety-free.

"If I work for COVID patients God will take care of my family", "Family should not get infected", "requested husband who is a health care worker not to do COVID duty, so that one parent is available for children", "whenever there was cough there was apprehension", "dealt intellectually and maintained safe distance", "got testing done two times and then went home to stay with family", "did not tell about COVID duty so now there is no fear", "Both Parents had Comorbidities",

\section{Theme 4: Coping strategies}

The participants reported the various coping strategies adopted by them, like prayer, exercises, inner peace, self-confidence, and mainly the support from family and friends.

"I used to pray", I spent time in exercises" "it's my family who supported me" "my friends helped me a lot

\section{Discussion}

The present study aimed at finding out the experiences of nurses who worked in COVID areas upon careful analysis and meaningful interpretation of data derived from recorded interviews of participants the researchers could enumerate that nurses experienced physical and psychological stressors while caring for COVID positive patients.

By and large fear and anxiety were the main stressors reported by the nurses which are consistent with other studies by Yan Zhang et al [11], Qian Liu [12]. Nurses also experienced helplessness, discouragement, and inability to help patients while caring for them. Since fear of exposure was always the mental focus, it prevented the nurses from spending a longer duration of time giving care to these patients. Death of young patients and instances of the quick progression of disease often produced helplessness, demotivation, and anger in these nurses. Some labeled this experience as an incident that would be forever etched into their memories with indelible ink.

Concerns for family members were another theme that came up during interviews. Nurses living alone worked more freely with a clear head than nurses who lived with families. They were always in fear of getting infected and in turn, had the morbid dread of infecting family members. Findings to this extent were reported by Niuniu et al [13], Nasrin Galehdar [14].

Experience with PPE was vividly described by the participants. Experiences ranged from mild discomfort to gastritis, weight loss, self pricking with needles, diminished vision and hearing. Though PPE proved to be a barrier between the patients and the nurses for disease transmission, yet at the same time, it was also an obstacle in rendering quality patient care. Often nurses reported incidents of slipping as the shoe covers were slippery and bulky this not only proved to be a hindrance in discharging quality patient care but also instilled fear of falls in the minds of nurses. The very nature of PPE limited mobility caused undue exhaustion, dehydration, and weight 
loss as reported by some of the nurses. During times of emergency, the fogging on the protective glasses made reading very difficult and loading medications was very challenging for some of the participants. Due to diminished hearing following instructions of the physician also proved to be taxing for some of the respondents. These experiences corroborate with research findings of the study by Qian Liu [12], Nasrin Galehdar [14].

Coping strategies as reported by our nurses are in line with the studies by, Yan Zhang et al [11], Qian Liu [12], Niuniu et al [13], ranging from faith in God, walk in parks, self-confidence, being knowledgeable about the disease, support from family and friends made the nurses resilient to work in COVID areas.

\section{Limitations}

Researchers could not be able to access the nursing personnel working in managerial positions because of their hesitation to participate in the study.

\section{Recommendations}

The study can be conducted in other various settings like autonomous hospitals, public and private hospitals and can be compared. A similar study can be done on other Health Care Personnel. Regular and continuous in-service training for health care providers on preparedness for pandemic management will be beneficial.

\section{Conclusion}

Nurses face lots of challenges while working during pandemics. They experience physical and psychological stressors and emotional challenges. Nurses also actually get infection; have the risk of getting infected, despite maintaining standard precautions.

Since nurses are resilient, they come out of their experiences with more professional and mental strength and motivation. Such experiences help the nurses to grow more professionally and individually and place them to be role models and mentors for junior nurses.

The responsibility of nursing administration was carried adequately for imparting ongoing in-service training to the nurses. Apart from that it is also imperative to provide them with adequate PPE / staffing, a harmonious and congenial working atmosphere, listen to their concerns with empathy while adequately counseling them so that they are suitably equipped to work in the clinical areas to provide quality patient care.

Conflict of Interest: The authors of this systematic review declare no conflict of interest.

\section{References}

1. Rajib, Acharya., Ph.D., Akash, Porwal., MPSA Vulnerability index for the management of and response to the COVID-19 epidemic in India: an ecological study Open Access Published: July 16, 2020DOI:https://doi.org/10.1016/S2214109X(20)30300

2. The Rise and Impact of COVID-19 in India, S. Udhaya Kumar, D. Thirumal Kumar, B. Prabhu Christopher, and C. George Priya Doss, Published online 2020 May 22. DOI: 10.3389/ fmed.2020.00250

3. Aliakbari, F., Hammad, K., Bahrami, M. Ethical and legal challenges associated with disaster nursing. Nurse Ethics. 2015;22:493-503

4. O'Boyle, C., Robertson, C., Secor-Turner, M. Nurses' beliefs about public health emergencies: fear of abandonment. $\mathrm{Am} \mathrm{J}$ Infect Control. 2006;34:351-357

5. Kim, Y. Nurses' experiences of care for patients with Middle East respiratory syndrome-corona virus in South Korea. Am J Infect Control. 2018; 46:781-787.

6. O'Boyle, C., Robertson, C., Secor-Turner, M. Nurses' beliefs about public health emergencies: fear of abandonment. $\mathrm{Am} \mathrm{J}$ Infect Control. 2006; 34:351-357.
7. Kang, L., Li, Y., Hu, S. The mental health of medical workers in Wuhan, China dealing with the 2019 novel coronavirus. Lancet Psychiatry. 2020 [PMC free article] [PubMed] [Google Scholar] [Ref list]

8. Mak, W.W.S., Law, R.W., Woo, J. Social support and psychological adjustment to SARS: the mediating role of selfcare self-efficacy. Psychol Health. 2009; 24:161-174. [PubMed] [Google Scholar] [Ref list]

9. Main, A., Zhou, Q., Ma, Y. Relations of SARS-related stressors and coping to Chinese college students' psychological adjustment during the 2003 Beijing SARS epidemic. J Counsel Psychol. 2011;58:410

10. Mishra, P., Bhadauria, U.S., Dasar, P.L. Knowledge, attitude and anxiety towards pandemic flu a potential bioweapon among health professionals in Indore City. Przegl Epidemiol. 2016;70 41-5, 125-7. [PubMed] [Google Scholar] [Ref list]

11. Yan, Zhang., Lili, Wei., Huanting, Li., Yueshuai, Pan., Jingyuan, Wang., Qianqian, Li., Qian, Wu., Holly, Wei ., The Psychological Change Process of Frontline Nurses Caring for Patients with COVID-19 during Its Outbreak, Issues Mental Health Nursing, 2020 Jun;41(6):525-530.doi: 10.1080/01612840.2020.1752865. E pub 2020 Jun 4.

12. Qian, Liu., Dan, Luo., Joan E, Haase., Qiaohong, Guo., Xiao Qin, Wang., Shuo, Liu ., Lin, Xia., Zhongchun, Liu., Jiong, Yang., Bing Xiang, Yang., The experiences of health-care providers during the COVID-19 crisis in China: a qualitative study, 2020 Jun;8(6):e790-e798. doi: 10.1016/S2214-109X(20)30204-7. Epub 2020 Apr 29.PMID: 32573443,PMCID: PMC7190296 DOI: 10.1016/S2214-109X(20)30204-7

13. Niuniu, Sun., Luoqun, Wei., Suling Shi., Dandan, Jiao., Runluo, Song., Lili, Ma., Hongwei, Wang., Chao, Wang., Zhaoguo, Wang., Yanli, You., Shuhua, Liu., Hongyun WangA qualitative study on the psychological experience of caregivers of COVID-19 patients, Am J Infect Control 2020 Jun;48(6):592598. doi: 10.1016/j.ajic.2020.03.018. Epub 2020 Apr 8.

14. Nasrin,Galehdar., Aziz, Kamran., Tahereh, Toulabi., Heshmatolah, Heydari., Exploring nurses' experiences of psychological distress during care of patients with COVID-19: a qualitative study, BMC Psychiatry, 2020 Oct 6;20(1):489, doi: 10.1186/s12888-020-02898-1. 